\title{
Properties of Low Density Foamed Concrete for Building Construction Using Anionic Surfactants of Synthetic and Natural Materials
}

\author{
Jeong, Ji-Yong Kim, Jin-Man* \\ Department of Architectural Engineering, KongJu National University, SeoBuk Gu, Cheonan, 330 717, Korea
}

\begin{abstract}
The surfactants facilitate the formation of foam bubbles under a proper condition and provide stability of foam bubbles by decreasing the surface tension of solutions and increasing the viscosity of foam surface. However, there have been almost no practical data of foam concrete in this regard so far. This study aims to understand the effects of foaming agents such as anionic synthetic surfactant and anionic natural material surfactant on the low density foamed concrete. From the experiment, the vegetable soap of anionic natural material surfactants showed a higher foaming rate, more open pores, slightly lower compressive strength, and a higher permeability coefficient compared to the vegetable soap of anionic synthetic surfactants. It is believed that the natural material surfactants make not only the surface tension of the solution low but also the viscosity of slurry high.
\end{abstract}

Keywords : low density foamed concrete, surfactant, surface tension, assisting drainage, permeability coefficient

\section{Introduction}

Aerated concrete is a type of lightweight concrete that applies foam bubbles in the cement paste, and it is classified into prefoaming method and postfoaming method depending on the application time of pores. The prefoaming method mixes prefoamed foam in the slurry whereas the postfoaming method uses foam bubbles that are generated by hydrogen gas produced by the reaction of aluminum powder mixed in the slurry and primary hydrate.

The ALC(Autoclaved Lightweight Concrete), a renowned aerated concrete created by the postfoaming method, demonstrates excellent features in mechanical

Received : June 17, 2011

Revision received : September 30, 2011

Accepted : October 6, 2011

* Corresponding author : Kim, Jin-Man

[Tel: 82-41-521-9332, E-mail: jmkim@kongju.ac.kr]

(c)2011 The Korea Institute of Building Construction, All rights reserved. and heat resistant properties compared to the prefoamed products with the same density, but the density is limited to 3 types of $0.3,0.5$ and $0.7 \mathrm{t} / \mathrm{m}^{3}$, so its application is not diverse. On the other hand, aerated concrete of the prefoaming method, which is the main subject in the study, is inferior in strength and heat resistant properties compared to the ALC, but the density can be extended to more than $0.7 \mathrm{t} / \mathrm{m}^{3}$ so it can be used for different purposes and also be used for a purpose distinctive from ALC since it has a quality of making the sound absorbing rate and permeability better by forming continuous pores or open pores in the low density area. Even though ALC is limited to factory products manufactured in the hydrothermal reaction condition of high temperature and pressure, the aerated concrete of prefoaming method can be used for factory products as well as castin-place materials such as plastering heating floors.

It is the density that has significant impacts on different physical properties of aerated concrete such as strength, thermal characteristics, etc.[2] Density is 
adjusted by the mixture of foam bubbles so the characteristics of foam bubbles are essential factors in manufacturing the aerated concrete. After the surface tension of liquid is reduced by surfactant, foam bubbles are created by adding external force to thesolution. As time passes, the thickness of the foam wall decreases and ultimately the foam bubbles are combined[3]. When aiming to closed pores, antifoaming should be avoided and when aiming to open pores, an appropriate condition for antifoaming should be provided.

In the antifoaming of foams, the surface tension and molecular activities of the surfactant along with the coalescence of foam bubbles and drainage have significant influences. However, there is no qualitative study that reports the effects of these factors on the features of aerated concrete.

Under such conditions, the study qualitatively analyzed the effects of surface tension and molecular activity of solution that uses surfactant, coalescenceof foamed foam bubbles and drainage on the characteristics of lightweight aerated concrete when anionic synthetic surfactant and anionic natural surfactant which are used for insulation in the construction sites are applied to the aerated concrete of density lower than $0.6 \mathrm{t} / \mathrm{m}^{3}$.

\section{Foam formation and characteristics of antifoaming}

\subsection{Surface tension of Surfactant and Solution}

Foam bubbles are formed under the condition where air can be flowed into the solution through stirring or air injection after reducing the surface tension of solution with the surfactant. The surface tension of water is generally $72 \sim 73 \mathrm{mN} / \mathrm{m}$ but the surface tension of solution with the surfactant lowers to $40 \sim 50 \mathrm{mN} / \mathrm{m}[4]$ so foam bubbles are easily formed.
Increase of surfactant concentrationis not proportional to decline of surface tension[5,6,7,8] and this is because the CMC (Critical Micelle Concentration) is consistent according to the surfactant[9]. However, the molecular activity varies depending on the type of the surfactant so the surface tension differs as well[4].

The lower the surface tension of solution is, the more easily the form bubbles form. Therefore, it is necessary to consider the type of surfactant to form foam bubbles.

\subsection{Antifoaming mechanism of foam}

It is the porosity that has the most important impact on the density of aerated concrete. Foam fraction is variably applied depending on the final usage of the hardened paste and used in the range of 25 80\% of total capacity of the hardened paste. When there are a small amount of foam bubbles, the distance between the foam bubbles is far, so they do not interfere with each other, but when there are a large amount of foam bubbles, the distance gets closer, and when more foam bubbles are formed, finally coalesced to each other. The combination of foam bubbles has a great influence on the size and distribution of foam bubbles[10]. When the combination of foam bubbles is active, the pores formed in the hardened paste are connected to each other resulting in open pores.

The development process of foam bubbles can be classified into 2 types. The first is combination of foam bubbles according to the vapour pressure deficit. The coalescenec of foam bubbles naturally occurs by the difference of vapour pressure in and out of the foam bubbles. Since the difference between pressures applied from the inside and the outside is in inverse proportion to the radius of foam bubble[11] so when the foam bubble is small, the inner pressure increases and the air moves 
through the foam lamella causing the smaller foam bubble to be absorbed to the bigger foam bubble as shown in Figure 1[10]. Second is the drainage. As shown in Figure 2, the vapour pressure of plateau boarder becomes lower than the pressure of the foam lamella so the liquid flows into the plateau boarders[12]. When the drainage takes place, the foam lamella becomes thinner, and foam bubbles combine each other.

\subsection{Viscosity of Solution and Antifoaming}

Generally, the lower the viscosity of liquid is, the faster the drainage occurs so the drying process of foam lamella speeds up. However, when surfactants are used, the viscosity of water increases due to the long chain on surfactant molecules so it slows down the flow and drainage rate of the liquid in the lamella[12], and ultimately slows down the drying process of foam bubbles.

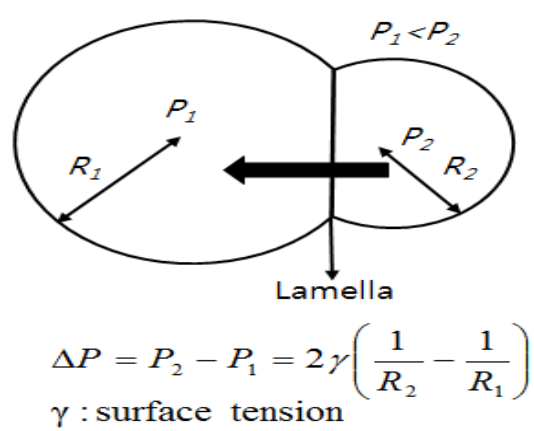

Figure 1. Model for the combination of foams

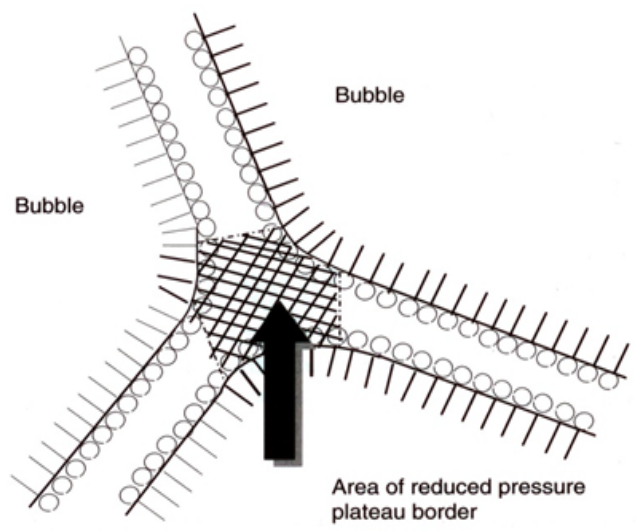

Figure 2. Plateau borders at lamella intersections
As shown in the study, the surfactant does not only make foaming easier but it also contributes to the stability of foam bubbles that cannot be easily controlled.

Table 1. Plan of experiment

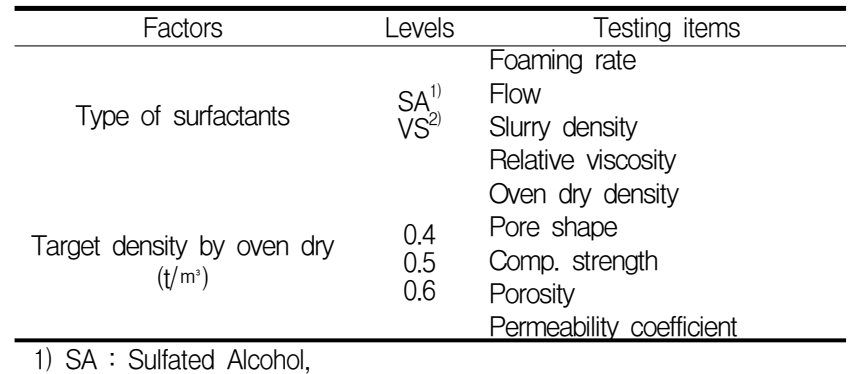

2) VS : Vegetable Soap

The effect of surfactant slowing down the antifoaming of foam bubbles is because surfactants increase the viscosity of solution. Since aerated concrete is a type where powder is dispersed in solution so when a factor other than the solution that promotes the antifoaming of foam bubbles exists, the movement will become more complex. However, the movement of foam bubbles in the slurry is influenced by the solution in its nature so the viscosity of solution would be the most significant factor that affects the stability of foam bubbles.

Aerated concrete encounters foam bubbles in the slurry form, but ultimately it is used in solid state so it is necessary to consider the characteristics of foam bubbles both in fresh and hardened form. David claimed that pores of foam bubbles in hardened paste are affected by viscosity of unset slurry[13]. Thereby, the viscosity of slurry is an important factor when creating aerated concrete.

Nevertheless, it is not clear what affects the stability of foam bubbles in slurry under the mixing condition with the same viscosity. As surfactants affect formation and stability of foam bubbles, it is estimated that it would have some effect on foam bubbles of aerated concrete and especially in the 
lowdensity aerated concrete that mixes a large amount of foam bubbles for the purpose of insulation, the lamellar is thin so there is a great deal of interfere between the foam bubbles, which may result in a great change in their features.

\section{Experiment Plan and Method}

\subsection{Experiment Plan}

Table 1 shows the experiment plan. For the anionic surfactants, SA of natural synthetic material and VS of natural material were used. In order to form open pores in a condition where a large amount of foam bubbles are used, the density was aimed at $0.4,0.5$ and $0.6 \mathrm{t} / \mathrm{m}^{3}$ under the oven dry condition. Table 2 illustrates the composition of mixtures with water-binder ratio being 40\%, concentration of surfactants $2 \%$, and molar ratio of $\mathrm{CaO} / \mathrm{SiO}_{2} \quad 1.0$ for curing of autoclave under temperature of $180{ }^{\circ} \mathrm{C}$ and pressure of 10 .

\subsection{Experiment Method}

Figure 3 is a schematic diagram of foam production method. Foam bubbles are produced using the method of bringing in the surfactant solution through the compressed air and carrying the solution through the tube packed with bead. The surfactant solution was diluted to $2 \%$ according to the water weight. The aerated concrete was produced for 3 minutes by adding foam bubbles to the paste composed of water, binder, and superplasticizer. The test object was molded using the cubic mold $(100 \times 100 \times 100) \mathrm{mm}$ for oven dry density, compressive strength and porosity, and using they cylinder mold $(0100 \times 200)$ $\mathrm{mm}$ for the permeability coefficient.

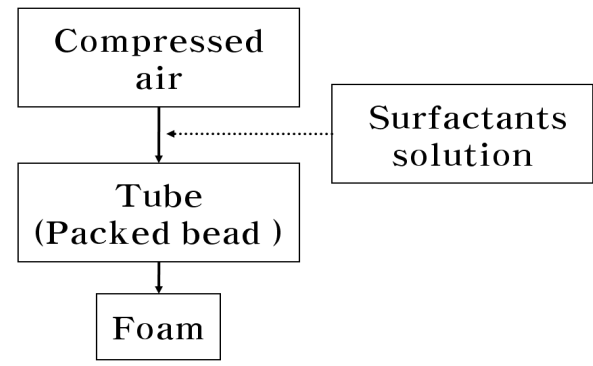

Figure 3. Schematic diagram of foam production method

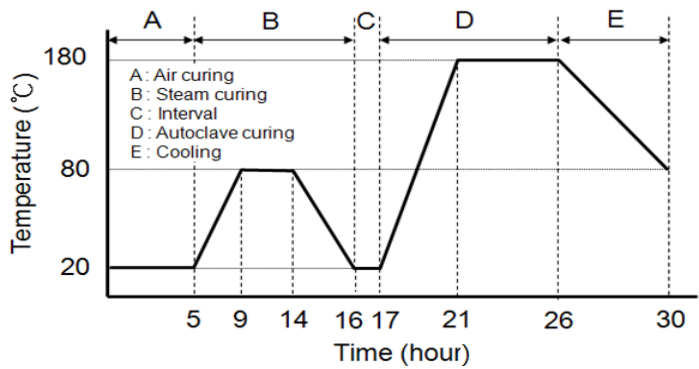

Figure 4. Curing process

Table 2. Composition of mixtures

\begin{tabular}{|c|c|c|c|c|c|c|c|c|c|c|c|c|c|c|c|c|c|}
\hline \multirow{2}{*}{$\begin{array}{l}\text { W/B } \\
(\%)\end{array}$} & \multirow{2}{*}{$\begin{array}{c}\text { Concentration of } \\
\text { surfactant } \\
(\%)\end{array}$} & \multirow{2}{*}{$\mathrm{C} / \mathrm{S}$ mol ratio } & \multirow{2}{*}{$\begin{array}{c}\text { Type of } \\
\text { surfactants }\end{array}$} & \multirow{2}{*}{$\begin{array}{c}\text { Target } \\
\text { density } \\
\left(\mathrm{t} / \mathrm{m}^{3}\right)\end{array}$} & \multirow{2}{*}{$\begin{array}{l}\text { Water } \\
\left(\mathrm{kg} / \mathrm{m}^{3}\right)\end{array}$} & \multicolumn{6}{|c|}{ Unit volume $\left(\ell / \mathrm{m}^{3}\right)$} & \multicolumn{6}{|c|}{ Unit weight $\left(\mathrm{kg} / \mathrm{m}^{3}\right)$} \\
\hline & & & & & & $\mathrm{PC}^{3)}$ & $Q^{4)}$ & $A C^{5)}$ & $\mathrm{CH}^{6)}$ & $A G^{7)}$ & Foam & $\mathrm{PC}$ & $Q$ & $A C$ & $\mathrm{CH}$ & $A G$ & Foam \\
\hline \multirow{6}{*}{40} & \multirow{6}{*}{2} & \multirow{6}{*}{1.0} & \multirow{4}{*}{$S A^{1)}$} & 0.4 & 157 & 67 & 54 & 8 & 9 & 14 & 691 & 210 & 135 & 21 & 10 & 17 & 10 \\
\hline & & & & 0.5 & 186 & 79 & 64 & 9 & 11 & 17 & 653 & 248 & 160 & 25 & 12 & 20 & 10 \\
\hline & & & & 0.6 & 214 & 91 & 74 & 11 & 13 & 19 & 579 & 286 & 184 & 29 & 14 & 23 & 9 \\
\hline & & & & 0.4 & 157 & 67 & 54 & 8 & 9 & 14 & 691 & 210 & 135 & 21 & 10 & 17 & 9 \\
\hline & & & \multirow[t]{2}{*}{$V^{2}$} & 0.5 & 186 & 79 & 64 & 9 & 12 & 17 & 653 & 248 & 160 & 25 & 12 & 20 & 9 \\
\hline & & & & 0.6 & 214 & 91 & 74 & 11 & 13 & 19 & 579 & 286 & 184 & 29 & 14 & 23 & 8 \\
\hline
\end{tabular}

1) SA : Sulfated Alcohol,

2) VS : Vegetable Soap,

3) PC : Portland Cement,

4) $Q:$ Quartz,

5) AC : Alumina Cement

6) $\mathrm{CH}:$ Calcium Hydroxide,

7) AG : Anhydrite Gypsum 
Figure 4 shows the curing process and it is made up of 3 stages: air curing, steam curing, and autoclave curing. The air curing that minimizes the loss of foam bubbles added to the paste was conducted for 5 hours with temperature of $20 \pm 2{ }^{\circ} \mathrm{C}$. The second stage, steam curing, was done to prevent any damage during the transferring process to the autoclave curing after it was removed from the mold. After raising the temperature at the rate of $15{ }^{\circ} \mathrm{C}$ /hour for 4 hours, $80{ }^{\circ} \mathrm{C}$ was maintained for 5 hours. The final stage, autoclave curing, is to produce Tobermorite by reacting $\mathrm{SiO}_{2}$ with $\mathrm{CaO}$ for strength development and it was executed under the condition of $180^{\circ} \mathrm{C}$ and pressure of 10 for 5 hours after raising the temperature at the rate of $40^{\circ} \mathrm{C} /$ hour for 4 hours.

The flow was measured according to the test method of KS F 4039 aerated concrete for cast-in-site and after hardening, the oven dry density was measured with KS F 2701 lightweight aerated concrete block. The compressive strength was measured by ASTM C 495-99a Standard test method for compressive strength of lightweight insulating concrete and the permeability coefficient was measured based upon KS F 2322 soil permeability test method since the permeability of low density foamed concrete is relatively high.

The slurry density was measured after mixing the cement paste with foam bubbles and stirring mixture for 3 minutes. The foaming rate was measured through the unit weight of foam bubbles. With Brookfield RVDV-II viscometer, the slurry viscosity was analyzed 2 minutes after stirring it and this is because the viscosity of slurry started to increase at this time.

The porosity was observed through an optical microscope of 10x magnifications. The porosity was measured with the Eq.(1) through the KS L 5110 cement gravity test after grinding some part of the test object because the saturated-surface-dry condition and the submerged weight could not be measured due to the open pores of low-density aerated concrete.

$$
P=\left(1-\frac{W}{\rho}\right) \times 100
$$

$\mathrm{P}=\operatorname{porosity}(\%), \mathrm{W}=$ oven $\operatorname{dry} \operatorname{density}\left(\mathrm{t} / \mathrm{m}^{3}\right)$, o=specific gravity

\subsection{Materials}

The synthetic surfactants include sulfuric acid and sulfated alcohol composed of monoesters, and the natural surfactant is a solution of alkali metal salt of carboxylic acid which was extracted from vegetable oil. The properties are shown in Table 3.

As for cement, ordinary Portland cement that satisfies the standards of KS L 5201 was used, and Alumina cement was used to prevent antifoaming of foam bubbles. Slaked lime was added for the promotion of hydration of calcium silicate compounds and anhydrite was added to prevent quick setting of Alumina cement. Table 4 illustrates the chemical properties, and naphthalene was used for the superplasticizer.

Table 3. Chemical and physical properties of surfactants

\begin{tabular}{lcccc}
\hline Type & $\begin{array}{c}\text { Active } \\
\text { Matter }\end{array}$ & $\begin{array}{c}\mathrm{Na}_{2} \mathrm{SO}_{4} \\
(\text { wt. \%) }\end{array}$ & Relative Viscosity $\left.{ }^{*} \%\right)$ & $\begin{array}{c}\text { Surface } \\
\text { tension }\end{array}{ }^{*}(\mathrm{mN} / \mathrm{m})$ \\
\hline $\mathrm{SA}^{1)}$ & 28.2 & 4 & 11.48 & 47 \\
$\mathrm{VS}^{2)}$ & 25.7 & & 16.39 & 38 \\
\hline 1) SA : Sulfated Alcohol, & & \\
2) VS : Vegetable Soap, & 2\%(by weight) &
\end{tabular}

Table 4. Chemical properties of using binders

\begin{tabular}{cccccccccc}
\hline Type & $\mathrm{SiO}_{2}$ & $\mathrm{Al}_{2} \mathrm{O}_{3}$ & $\mathrm{Fe}_{2} \mathrm{O}_{3}$ & $\mathrm{CaO}$ & $\mathrm{MgO}$ & $\mathrm{K}_{2} \mathrm{O}$ & $\mathrm{Na}_{2} \mathrm{O}$ & $\mathrm{SO}_{3}$ & Ig.loss \\
\hline $\mathrm{PC}^{1)}$ & 21.4 & 6.3 & 2.9 & 61.4 & 2.7 & 0.9 & 0.1 & 2.2 & 0.4 \\
$\mathrm{Q}^{2)}$ & 96.2 & 1.9 & 0.73 & & & & & & 1.2 \\
$\mathrm{AC}^{3)}$ & 4.2 & 54.7 & 0.6 & 36.9 & & 0.2 & 0.1 & 0.2 & 3.1 \\
$\mathrm{CH}^{4)}$ & & & & 68.3 & & & & & 31.7 \\
$\mathrm{AG}^{5}$ & 3.7 & 0.7 & 0.1 & 38.3 & & & & 54.4 & 2.8 \\
\hline 1) $\mathrm{PC}:$ : Portland Cement, & & & & & & \\
2) $\mathrm{Q}:$ Quartz, & & & & & & & \\
3) $\mathrm{AC}$ : Alumina Cement & & & & & & \\
4) $\mathrm{CH}:$ : Calcium Hydroxide, & & & & & & \\
5) $\mathrm{AG}$ : Anhydrite Gypsum & & & & & &
\end{tabular}




\section{Results}

The results of experiment on the low density foamed concrete with target density of $0.4 \sim 0.6$ $\mathrm{t} / \mathrm{m}^{3}$ which was produced using anionic surfactants composed of synthetic and natural materials are indicated in Table 5.

\subsection{Foaming Rate}

Foam bubbles are formed through stirring or air inflow after its surface tension decreases due to the surfactants. The property change of foam bubbles caused by the surfactants arises due to the activity of molecules which are made up of hydrophilic and hydrophobic groups, surface tension of solution and viscosity of foam lamella.

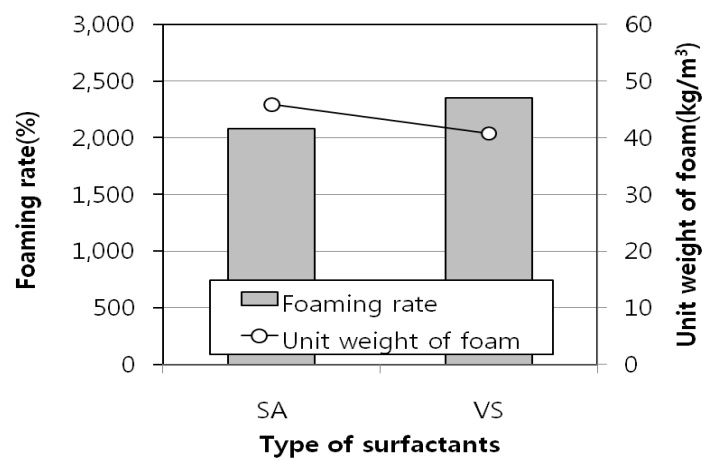

Figure 5. Foaming rate and unit weight of foam according to type of surfactants(SA : Sulfated Alcohol, VS : Vegetable Soap)

The foaming rate of SA and VS is $2080 \%$ and 2,355\% respectively and the unity weight was 45.9 and $40.7 \mathrm{~kg} / \mathrm{m}^{3}$. The difference in foaming rate was approximately 300\% and the gap in unit weight was about $5 \mathrm{~kg} / \mathrm{m}^{3}$ showing that VS forms more foam bubbles than SA. In the properties of foam, when it was unset, the viscosity, pore size and porosity change depending on the viscosity of the paste[13] but the foaming rate of solution with diluted surfactants was much better with VS as shown in Figure 5. This may be because the VS solution has lower surface tension.

\subsection{Relative Viscosity}

The viscosity of solution mixed with surfactants is influenced by molecules consisting of hydrophilic and hydrophobic groups. Especially, the hydrophobic group increases the viscosity in the form of long chain so it resists the flow of liquid generated from the foam lamella[12].

The relative viscosity of solution of SA and VS was 11.48 and $16.39 \%$ respectively, indicating that VS is higher as in the relative viscosity when the foamed concrete was unset. The relative viscosity of SA and VS is lowest when the target density is 0.5 $\mathrm{t} / \mathrm{m}^{3}$ and is high when the target density is 0.4 and $0.6 \mathrm{t} / \mathrm{m}^{3}$ as shown in Figure 6. This is due to the impact of the paste without foam bubbles when the density is over $0.5 \mathrm{t} / \mathrm{m}^{3}$ resulting in decrease in foam usage and increase afterwards. When the density is less than $0.5 \mathrm{t} / \mathrm{m}^{3}$, it is due to the impact of the hydrophobic group of surfactant molecules caused by a great deal of foam bubbles.

Table 5. Results of experiment

\begin{tabular}{|c|c|c|c|c|c|c|c|c|c|c|}
\hline $\begin{array}{c}\text { Type of } \\
\text { surfactants }\end{array}$ & $\begin{array}{c}\text { Target } \\
\text { density } \\
\left(\mathrm{t} / \mathrm{m}^{3}\right)\end{array}$ & $\begin{array}{c}\text { Foaming rate } \\
(\%)\end{array}$ & $\begin{array}{l}\text { Unit weight of } \\
\text { foam }\left(\mathrm{kg} / \mathrm{m}^{3}\right)\end{array}$ & $\begin{array}{c}\text { Flow } \\
(\mathrm{mm})\end{array}$ & $\begin{array}{c}\text { Slurry } \\
\text { density } \\
\left(\mathrm{t} / \mathrm{m}^{3}\right)\end{array}$ & $\begin{array}{c}\text { Relative } \\
\text { viscosity (\%) }\end{array}$ & $\begin{array}{c}\text { Oven dry } \\
\text { density } \\
\left(\mathrm{t} / \mathrm{m}^{3}\right)\end{array}$ & $\begin{array}{c}\text { Compressive } \\
\text { strength } \\
(\mathrm{MPa})\end{array}$ & $\begin{array}{c}\text { Porosity } \\
(\%)\end{array}$ & $\begin{array}{c}\text { Permeability } \\
\text { coefficient } \\
\text { (cm/sec) }\end{array}$ \\
\hline \multirow{3}{*}{$S A^{1)}$} & 0.4 & & & 207 & 0.55 & 46.8 & 0.40 & 1.52 & 82 & 0.083 \\
\hline & 0.5 & 2,080 & 45.9 & 220 & 0.68 & 42.9 & 0.51 & 2.66 & 78 & 0.026 \\
\hline & 0.6 & & & 235 & 0.80 & 62.3 & 0.57 & 2.99 & 74 & 0.000 \\
\hline \multirow{3}{*}{$\mathrm{VS}^{2)}$} & 0.4 & & & 208 & 0.55 & 53.2 & 0.40 & 1.26 & 82 & 0.256 \\
\hline & 0.5 & 2,355 & 40.7 & 222 & 0.67 & 48.1 & 0.51 & 2.21 & 77 & 0.036 \\
\hline & 0.6 & & & 232 & 0.74 & 61.0 & 0.56 & 2.97 & 75 & 0.014 \\
\hline
\end{tabular}




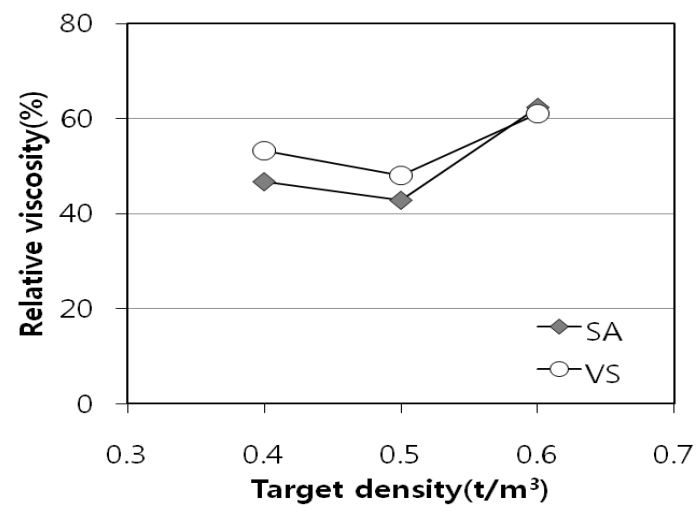

Figure 6. Relative viscosity according to target density(SA : Sulfated Alcohol, VS : Vegetable Soap)

\subsection{Flow}

The flow of concrete varies depending on types and properties including unit quantity, binder, compound, admixture, aggregate, etc. Because the flow of concrete is determined by many factors, the study measured the flow according to the surfactant type with materials and mixing ratio being identical. As in Figure 7, SA and VA showed similar results but their flow increased according to the density. It is evaluated that the increase is caused by the increase of flow energy of slurry state. Even though there was a difference between SA and VS in the similarity of flow with the foaming rate, such result is produced because the surface tension of surfactants and viscosity of the foam lamella do not affect the flow of the paste.

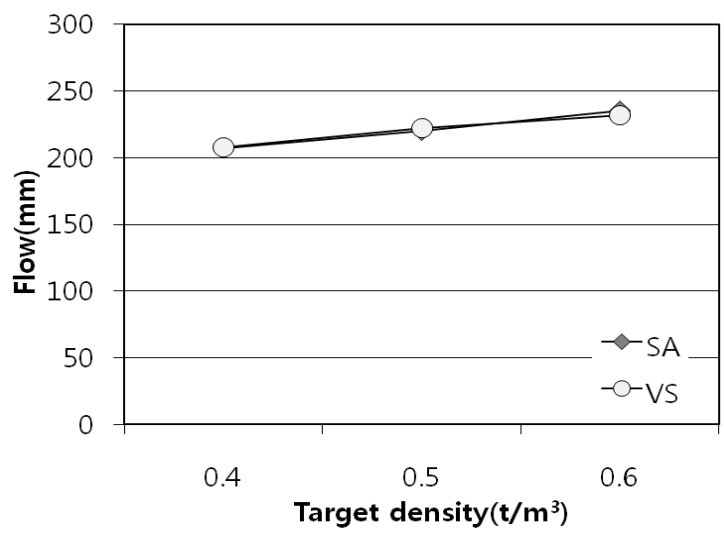

Figure 7. Flow according to target density(SA : Sulfated Alcohol, VS : Vegetable Soap)

\subsection{Density}

Figure 8 shows the slurry density and the oven dry density. The oven dry density measured according to the target density was 0.40, 0.51, and $0.57 \mathrm{t} / \mathrm{m}^{3}$ with SA and was $0.40,0.51,0.56 \mathrm{t} / \mathrm{m}^{3}$ with VS showing identical or similar results. The density of each surfactant was similar in all conditions except for $0.6 \mathrm{t} / \mathrm{m}^{3}$. This is because both VS and SA experience loss of foam bubbles during the production process with the solution of $2 \%$ concentration.

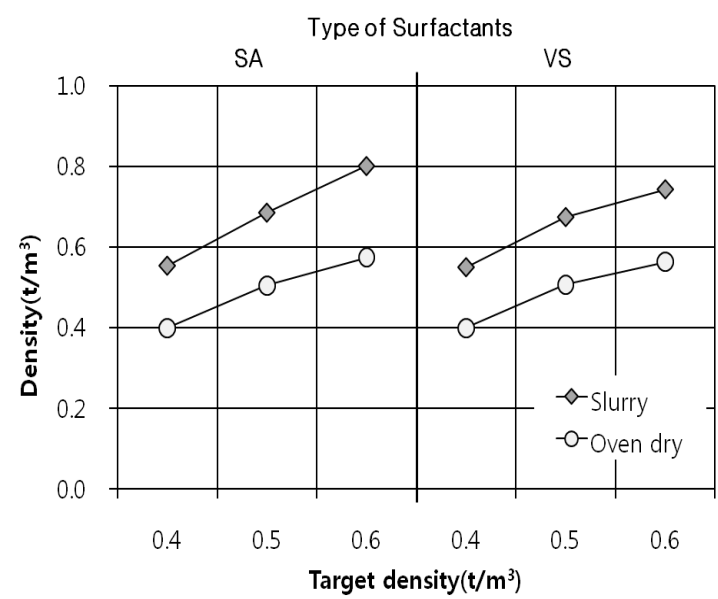

Figure 8. Slurry and oven dry density according to target density(SA : Sulfated Alcohol, VS : Vegetable

Soap)

The gap between slurry density and oven dry density increases when the amount of cement paste increases along with the density. As for the difference by the type of surfactants, both had similar results except when the target density was $0.6 \mathrm{t} / \mathrm{m}^{3}$. The density gap was $0.15 \mathrm{t} / \mathrm{m}^{3}$ when the target density was $0.4 \mathrm{t} / \mathrm{m}^{3}$, and when the target density was $0.5 \mathrm{t} / \mathrm{m}^{3}$, SA and VA was 0.18 and 0.17 $\mathrm{t} / \mathrm{m}^{3}$ but at $0.6 \mathrm{t} / \mathrm{m}^{3}$, SA was $0.23 \mathrm{t} / \mathrm{m}^{3}$ and VS was $0.18 \mathrm{t} / \mathrm{m}^{3}$ showing a slight difference.

\subsection{Porosity}

Density and porosity has a very close connection[14]. 
The porosity of SA and VS was very similar. AS shown in Figure 9, the porosity of SA and VS was $82 \%$ when the target density was $0.4 \mathrm{t} / \mathrm{m}^{3}$ and $78 \%$ and $77 \%$ respectively when the target density was $0.5 \mathrm{t} / \mathrm{m}^{3}$. With the target density being $0.6 \mathrm{t} / \mathrm{m}^{3}$, the porosity of both surfactants was $74 \%$ and $75 \%$. Considering their similarity in oven dry density, it can be evaluated that the change of porosity varies depending on the density.

Generally, porosity and permeability coefficient have a close connection, but they do not have much influence as a single factor[15]. Depending on the type of surfactants, the pore shape and the open pores vary, and the permeability coefficient varies as well. However, with the same mixing ratio, the change of porosity is thought to be greatly influenced by the density.

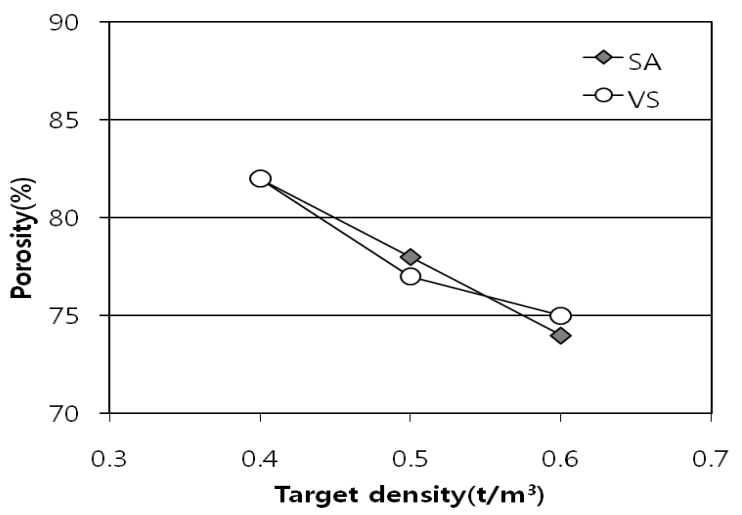

Figure 9. Porosity according to target density(SA : Sulfated Alcohol, VS : Vegetable Soap)

\subsection{Shapes}

Figure 10 shows the shapes of dried foamed concrete through an optical microscope of $10 \mathrm{x}$ magnifications. The pore size of SA is smaller than that of VS. The pore size according to the target density is similar at the point $0.5 \mathrm{t} / \mathrm{m}^{3}$ and 0.6 $\mathrm{t} / \mathrm{m}^{3}$, but it gets bigger at $0.4 \mathrm{t} / \mathrm{m}^{3}$. This is true for both SA and VS. The bigger pore size at $0.4 \mathrm{t} / \mathrm{m}^{3}$ may be due to coalescenceof foam bubbles when the interference between foam bubbles increases.

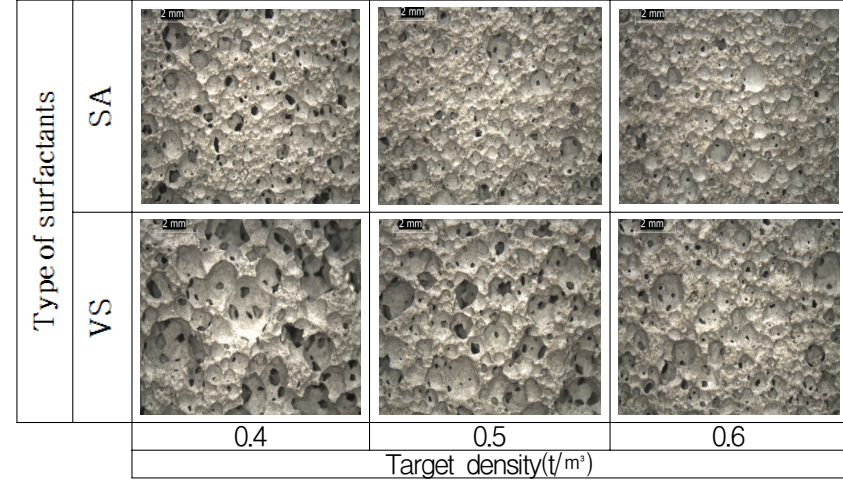

Figure 10. Shapes of low density foamed concrete $(\times 10)(\mathrm{SA}$ : Sulfated Alcohol, VS : Vegetable Soap)

The shapes of foam lamella form open pores with the lamellas destroyed. As the target density decreases, bigger open pores are formed and VS forms bigger open pores than SA under the same density condition. Since VS has a higher foaming rate due to surface tension and viscosity, it has thin lamella and creates bigger pores. When the lamella is thinner, the interference between foam bubbles become easier and coalescence becomes more active in the mixing process. Foam bubbles change after going through a wetting stage where foam bubbles maintain their old forms without any interference, a transition stage where the foam lamella becomes thin due to drainage, and a dry stage where the foam lamellas change into polyhedral shapes[12]. The differences of open pores are caused by the thickness of foam lamella in the wetting stage, viscosity and drainage velocity in the transit stage, and thickness and drying rate in the dry stage. The foamed concrete of the study used alumina concrete for fast stabilization of foam bubbles so that it could boost the solidification speed of the paste in order to form open pores.

Therefore, open pores are formed bigger with VS as the interference of foam bubbles increase because of the difference of foam lamellas by the foaming rate within the limited time. 


\subsection{Permeability Coefficient}

As in Figure 10, the formation of open pores resulted from the collapse of foam lamellas affects the permeability of aerated concrete. Figure 11 shows permeability coefficient according to the target density, and VS shows higher permeability coefficient compared to SA. When the target density is $0.4 \mathrm{t} / \mathrm{m}^{3}$, the permeability coefficient was the highest. At 0.4 $\mathrm{t} / \mathrm{m}^{3}$, the permeability coefficient of SA was $0.083 \mathrm{~cm} / \mathrm{sec}$ and it was $0.256 \mathrm{~cm} / \mathrm{sec}$ with $\mathrm{VS}$, which is twice the value of $\mathrm{SA}$. When the target density was 0.5 and $0.6 \mathrm{t} / \mathrm{m}^{3}$, the permeability coefficient of SA was 0.026 and $0.000 \mathrm{~cm} / \mathrm{sec}$ whereas it was 0.036 and $0.014 \mathrm{~cm} / \mathrm{sec}$ with $\mathrm{VA}$.

The reason for $0.000 \mathrm{~cm} / \mathrm{sec}$ is because the movement of water might be too slow as the number and size of open pores are small as in Figure 10.

The biggest change of the permeability coefficient is that it was the highest when the target density was $0.4 \mathrm{t} / \mathrm{m}^{3}$. Continuous pores are formed due to drainage in the foam lamella and when the target density is 0.5 and $0.6 \mathrm{t} / \mathrm{m}^{3}$, there is little interference between foam bubbles in unset state. When the target density is $0.4 \mathrm{t} / \mathrm{m}^{3}$, numerous foam bubbles are used, increasing the interference between foam bubbles and narrows the intervals so it increases the number of continuous pores as well as the permeability coefficients.

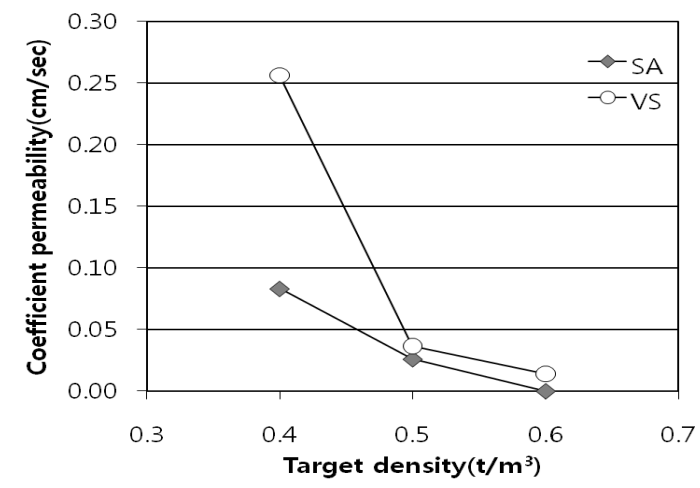

Figure 11. Coefficient permeability according to target density(SA : Sulfated Alcohol, VS : Vegetable Soap)

\subsection{Compressive Strength}

As for the compressive strength according to type of surfactants, when the target density was $0.4 \mathrm{t} / \mathrm{m}^{3}$ and $0.5 \mathrm{t} / \mathrm{m}^{3}$, SA was relatively high but when the density was $0.6 \mathrm{t} / \mathrm{m}^{3}$, it was similar to VA. The compressive strength of SA was $1.52 \mathrm{MPa}, 2.66$ $\mathrm{MPa}$, and $2.99 \mathrm{MPa}$ and as for VS, it was $1.26 \mathrm{MPa}$, 2.2 $\mathrm{MPa} 1$, and 2.97 $\mathrm{MPa}$ as in Figure 12.

In cement paste and mortar, porosity and compressive strength are in inverse proportional to each other, and the hardened cement is very complex because of factors such as micro cracks of transition zone between aggregate and cement matrix[16]. However, the study is conducted without aggregate, and since the mixing ratio and density were identical, they had similar results in porosity and oven dry density. They only had changes in shapes of pores and open pores. At the target density of $0.6 \mathrm{t} / \mathrm{m}^{3}$, there is little change in shapes of pores since there is not much interference between foam bubbles, and at target density of $0.4 \mathrm{t} /$ $\mathrm{m}^{3}$ and $0.5 \mathrm{t} / \mathrm{m}^{3}$, the shape of VS shows a bigger change than SA due to the difference in the interference between foam bubbles, resulting in difference in the compressive strength.

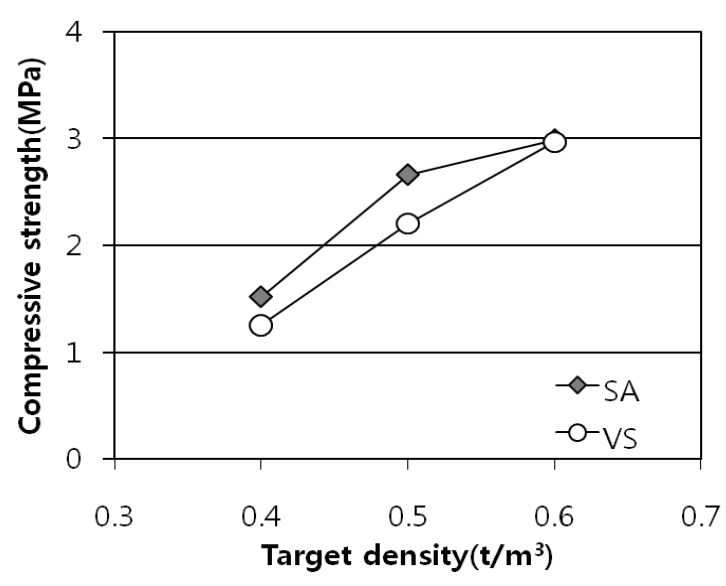

Figure 12. Compressive strength according to target density(SA : Sulfated Alcohol, VS : Vegetable Soap) 


\section{Conclusions}

1) The surfactants composed of natural materials $(\mathrm{VA})$ have a foaming rate $300 \%$ higher than the synthetic surfactants (SA) so it can form more foam bubbles with a relatively little amount of solution and its foam lamella is thinner.

2) The flow according to the type of surfactant is similar regardless of the type of resin so it does not affect the liquidity of aerated concrete.

3) The differences in slurry density and oven dry density vary depending on the amount of cement paste but the densities are similar depending on the type of surfactants.

4) The pore size and open pores are greater and higher with the surfactant of natural material than the surfactant of synthetic material. Pores and open pores are formed more when the oven dry density is $0.4 \mathrm{t} / \mathrm{m}^{3}$ compared to the point of $0.5 \mathrm{t} / \mathrm{m}^{3}$ and $0.6 \mathrm{t} / \mathrm{m}^{3}$.

5) The permeability coefficient was higher with the surfactant of natural material and the figure was higher when the target density was $0.4 \mathrm{t} / \mathrm{m}^{3}$. At the oven dry density of $0.5 \mathrm{t} / \mathrm{m}^{3}$ or higher, the permeability coefficient increases and this is resulted from the increased number of open pores which are produced by interference between pores and drainage of foam lamella.

6) The compressive strength of synthetic surfactant is relatively high when the target condition is at $0.4 \mathrm{t} /$ $\mathrm{m}^{3}$ and $0.5 \mathrm{t} / \mathrm{m}^{3}$ but was similar at $0.6 \mathrm{t} / \mathrm{m}^{3}$. Due to the properties of surfactants, the compressive strength changed a little because of pore shape, size of open pores and amount of formation at the oven dry density of $0.5 \mathrm{t} / \mathrm{m}^{3}$.

\section{Acknowledgement}

This work was supported by the Grant of the Korean Ministry of Education, Science and Technology(The Regional Core Research Program/Zero Energy Green Village Technology Center).
This work was supported by the Human Resources Development of the Korea Insitute of Energy Technology Evaluation and Planning(KETEP) grant funded by the Korea government Ministry of Knowledge Economy(No. 20114010203040)

\section{References}

1. Kim JM, Kang C. Engineering Properties of Sound Absorbing Foamed Concrete Using Bottom Ash Depending on Mix Factors. Journal of the Korea Institute of Building Construction. 2009 Oct:9(5): 65-72.

2. Kim JM, Choi HG, Park SG. An Experimental Study on the Pore Structure and Thermal Properties of Lightweight Foamed Concrete by Foaming Agent Type. Journal of the Korea Institute of Building Construction. 2009. Aug;9(4):63-73.

3. Kim JM, Kwak EG, Oh KC, Kang C. Properties of Bubble According to Types and Concentrations of Concrete Foaming Agent. Journal of the Korea Concrete Institute. 2011 Apirl;23(2): 151-8.

4. Holmberg K, J ö nsson B, Kronberg B, Lindman B. Surfactants and Polymers in Aqueous Solution. 2nd edition. Chichester, West Sussex England (UK): John wiley \& sons; 2003. p. 1-2

5. Moilliet J, Collie B. Surface Activity. E\&F Princeton (NJ): Van Nostrand; 1961. 518 p.

6. Tsujii K. Surface Activity. San Diego. California (CA): Academic Press; 1998. 245 p.

7. Yalkowsky SH. Solubility and Solubilization in Aqueous Media. Washington DC: American Chemical Society; 1999. 464 p.

8. Porter MR. Handbook of Surfactants. 2nd edition. London, New York: Blackie Academic \& Professional; 1994. 324 p.

9. David R. Karsa, Surfactants in Polymers, Coatings, Inks and Adhesives. Vol1. Oxford, England: Blackwell Publishing; 2003. p. 219-20.

10. Kasai Y. [New Admixtures for Cement \& Concrete]. Tokyo(Japanese): Technique-Lecture Hal; 2007 p. 272-80. Japanese.

11. Moore WJ. Physical Chemistry. 4th edition. Englewood Cliffs. NJ: Prentice Hall; 1972. 977 p.

12. David $\mathrm{R}$ Karsa. Surfactants in Polymers, Coatings, Inks and Adhesives. Vol1. Oxford, England: Blackwell Publishing; 2003. p. 95-9

13. David $R_{0}$ Karsa. Surfactants in Polymers, Coatings, Inks and Adhesives. Vol1. Oxford, England: Blackwell Publishing. ; 2003 p. 13-5

14. Kearsley EP, Wainwright PJ. Porosity and permeability of foamed concrete. Cement and Concrete Research. 2001 May; 31(5): 805-12.

15. Nyame BK, Illston JM. Relationship between permeability and pore structure of hardened cement paste. Magazine of Concrete and Research. 1981 Sep;33(116): 139-46.

16. Mehta PK, Monteiro PJ. Concrete, Microstructure, Properties, and Materials. 3th edition. New York: McGraw-Hill; 2004. p. 49-67. 